\title{
In favour of a Millian proposal to reform biomedical research
}

\author{
Julian Reiss
}

Received: 1 February 2009 / Accepted: 23 July 2010 / Published online: 9 September 2010

(C) The Author(s) 2010. This article is published with open access at Springerlink.com

\begin{abstract}
One way to make philosophy of science more socially relevant is to attend to specific scientific practises that affect society to a great extent. One such practise is biomedical research. This paper looks at contemporary U.S. biomedical research in particular and argues that it suffers from important epistemic, moral and socioeconomic failings. It then discusses and criticises existing approaches to improve on the status quo, most prominently by Thomas Pogge (a political philosopher), Joseph Stiglitz (a Nobel-prize winning economist) and James Robert Brown (a philosopher of science). Finally, it sketches an alternative proposal and argues for its superiority. The proposal has four components: changing the intellectual property regime; instituting independent clinical research; aligning innovators' and patients' interests; and enacting additional regulation.
\end{abstract}

Keywords Biomedical research · John Stuart Mill · Global Justice · Methodology

\section{Introduction}

One way to make philosophy of science more socially relevant is to attend to specific scientific practises that affect society to a great extent. Some 40 or 50 years ago, there was a neat division of labour between philosophers of science examining the conceptual, metaphysical and epistemological aspects and historians and sociologists examining actual scientific practice in its institutional, historical, social, economic, political and moral aspects. This division of labour has now largely been given up, partly because the pursuit of the purely philosophical problem failed. There are few conceptual, metaphysical or epistemological claims that are universally true, true

\footnotetext{
J. Reiss $(\bowtie)$

Faculty of Philosophy, Erasmus University, 3000 DR Rotterdam, The Netherlands

e-mail: reiss@fwb.eur.nl
} 
independently of their historical and institutional context. If this is the case, it immediately follows that philosophy must take that context into account if it still aims for true or at least useful principles.

The practise I look at in some detail here is contemporary-mostly U.S.biomedical research. I will argue that biomedical research, as currently done, has important, and interrelated, epistemic, moral and socio-economic failings. But these have largely been ignored in the philosophy of science literature. ${ }^{1}$ The aim of this paper is to partially redress the balance and make the organisation of biomedical research a philosophy of science topic. In what follows, I will first motivate the topic by arguing that the regulation of biomedical research is something philosophers of science should worry about. I will then describe the status quo and the various ways in which it is deficient. After that I will discuss critically proposals that have been made to improve the situation and, finally, outline my own proposal.

\section{Why philosophers of science should worry about how to reform biomedical research}

Some readers with a philosophy of science background may be sympathetic to the concerns regarding biomedical research (BMR) voiced here but wonder why the problem of how to organise research is their's. Aren't the metaphysical and epistemic dimensions of science the subject of the philosophy of science, and aren't there specialistssuch as bioethicists or medical ethicists - better qualified to deal with this issue? Let me adduce five arguments to the effect that this way of thinking would be mistaken.

\subsection{Institutional design has epistemic implications}

Social epistemologists locate rationality and objectivity not in individuals, their motives and causes of action, but rather in the institutions and procedures of knowledge acquisition. In the words of one proponent (Kitcher 1993, 305): 'particular kinds of social arrangements make good epistemic use of the grubbiest motives'. Helen Longino similarly argues that (Longino 1990, 74): 'Objectivity... is a characteristic of a community's practice of science rather than of an individual's, and the practice of science is understood in a much broader sense than most discussions of the logic of scientific method suggest'.

To the extent that philosophers of science aim to exert normative power over science, they therefore have to assess the degree to which institutions in a given domain are conducive to rational and objective inquiry. One way to do so is to assess the institutions against an ideal such as Kitcher's 'well-ordered science' (Kitcher 2001) or Longino's four criteria of objectivity-recognised avenues for criticism, shared standards, community response and (tempered) equality of intellectual authority (op. cit.; Longino 2002).

\footnotetext{
${ }^{1}$ Notable exceptions include Adam (2008), Biddle (2007), Brown (2002, 2004, 2008), Kincaid and McKitrick (2007), and Worrall (2002).
} 
Below, I will follow a different path and assess the output of BMR against the standards it sets itself. Partly this has to do with a contextualist perspective I am assuming. I will introduce it next.

\subsection{Philosophy of science without practise is impoverished}

There is another reason for why philosophy of science must attend to scientific practise. A number of philosophers have convincingly argued that there is no unique standard of scientific rationality, valid independent of the historical details and the purpose of the inquiry. To the contrary, scientific standards are valid, at best, locally and relative to the given context in which the inquiry is made (e.g., Kincaid 2004; Cartwright 2006). Without the context of specific queries, given by the researchers' purposes, standards, financial, technological and ethical constraints, assessments of the used methods will be mere intellectual parlour games.

BMR, then, may act as a case study for such contextual philosophy of science investigations as much as any other practise. But there are additional reasons to believe that this type of research lends itself particularly well to a study in 'how to make philosophy of science more socially relevant'. Unlike, say, those of many parts of theoretical physics, the products of BMR are of immediate social value, and in many cases essential for people's survival. Hence, and I will argue this in slightly more detail in a moment, factual and normative issues are more tightly interwoven here than in other areas, which makes them both harder but also more important to address. Experimentation is both more ethically challenging as well as less informative than in other domains. One aspect that characterises especially medical research is that there is no 'grand theory' such as Newton's, Einstein's or Darwin's that drives investigations, a reason that makes much of the theory-centred philosophy of science-positivist and post-positivist—difficult to apply.

\subsection{Ethical aspects cannot safely be ignored by philosophers of science}

Another reason to attend to the details of scientific practise has to do with the collapse of the fact/value dichotomy (Putnam 2002; see also Kincaid et al. 2007; Douglas, this volume). According to defenders of the dichotomy, there is a realm of 'facts' that exists separately from and uninfluenced by value judgements, has its own methods of investigation and its own qualities (such as objectivity). Facts can influence value judgements (for instance by the principle that if $S$ cannot do $X, S$ is under no obligation to do $X$ ) in a way that value judgements do not and should not influence the existence of and judgements about facts.

One line of argument against the dichotomy maintains that facts cannot neatly be separated from values because the very terms used in descriptions contain factual and evaluative components (probably more so for 'rape', 'cruel' and 'inflation' than for 'electron', 'spin' and 'red shift'). This is certainly true for much of BMR if for no other reason than that 'disease' itself is a value-laden concept. Importantly, the factual and evaluative aspects cannot be divorced in a way that would allow a division of labour between methodologists and ethicists. Defining a disease and designing appropriate 
methods for diagnosis and therapy are often interdependent, for instance. Therefore, focusing on the epistemic and metaphysical aspects and at the same time leaving the moral aspects to bioethicists is not an option for the philosopher of science, at least not in this area.

\subsection{Philosophers of science are well positioned to contribute to improving BMR}

The other side of the fact/value entanglement thesis is that normative judgements about how to organise BMR shouldn't be left to ethicists alone. The arguments that have been levied against current BMR do not just target skewed research priorities (for instance, by discriminating against diseases of ethnic minorities and the poor in the Western world, or the diseases of the global poor) and other ethical aspects, they also find fault with the more epistemic components of research, for instance, by pointing out that certain methods are ill-suited to realise particular goals independently of whether or not these goals are worth pursuing. Philosophers of science are (or should be) experts in these epistemic and methodological questions and should therefore play a role in designing epistemically and morally/socio-economically sound research institutions.

\subsection{No-one else is doing it}

A final reason for philosophers of science to engage with questions about the organisation of BMR is that others, to the extent that the task is their's, are simply not doing their job. A recent article by Michael Selgelid describes the situation in bioethics (Selgelid 2005, 273):

A situation analogous to the 10/90 divide in medical research [i.e., that $90 \%$ of research funds are used to investigate diseases causing $10 \%$ of the global disease burden] apparently holds true for research in bioethics. A quick flip through most bioethics texts and journals (or a visit to any number of websites) reveals attention on abortion, euthanasia, assisted reproduction, genetics, and doctor-patient relationships. To a large extent the issues examined one way or another involve advanced technologies or expensive interventions available primarily in wealthy developed nations. 'Distribution of resources' is a common topic; but discussion here often (at least implicitly) concerns domestic allocation rather than issues of international justice.

There are some attempts of political philosophers concerned about matters of international justice to bring the problem to the fore, most notably in the writings of Thomas Pogge (e.g., Pogge 2005), ${ }^{2}$ but these remain scattered and unsatisfactory (see below). Relevant for the theme of this volume is a criticism I shall make below of these proposals, viz. that they suffer from a lack of understanding of the science of producing

\footnotetext{
${ }^{2}$ In a vein similar to Thomas Pogge, Mathias Risse also asks whether there is a human right to essential pharmaceuticals. But he explicitly excludes questions about how to incentivise research into new treatments for the poor (Risse, forthcoming, 629).
} 
medical treatments. I take it, then, that there are some at least prima facie good reasons for philosophers of science to think about the organisation of BMR.

\section{What's wrong with biomedical research?}

In this paper I will focus on (contemporary) BMR in the United States because (a) it is highly significant (about half of the research dollars spent on BMR world wide are spent in the U.S. ${ }^{3}$; (b) it is most intensely studied; and (c) to my knowledge, it is the most highly biased with respect to criteria I use below. ${ }^{4}$ Let me also focus on the more applied side of BMR, the one concerned with the production of treatment options for patients. I assume that the goal of BMR, thus understood and described in the most abstract terms, is to produce medical treatments that are both safe and effective at providing genuine medical benefit.

This goal has three interrelated dimensions: epistemic, moral and socio-economic. On the epistemic dimension, I ask whether the procedures and methods BMR implements are likely to generate the knowledge required for realising its goal. In particular, I ask whether its procedures and methods make it likely that the safety and efficacy of its products are known. On the moral dimension, I ask whether the research priorities of BMR are adequate. On the socio-economic dimension, I ask whether the goal is realised efficiently, measured both in terms of monetary costs as well as costs such as those related to lost human and animal welfare. Let us consider each of these in turn.

\subsection{Three dimensions of assessing biomedical practise}

\subsubsection{Epistemic failures}

The U.S. Center for Drug Evaluation and Research (CDER), the FDA's centre responsible for, among other things, regulating and supervising the safety of medical drugs and devices assesses whether the drugs pharmaceutical companies wish to market are safe and effective for the intended use (Chow and Liu 2002). The main source of evidence demonstrating that drugs are safe and effective are clinical trials. Indeed, under ideal conditions, a clinical trial can be shown to prove causal conclusions-if the conditions are met (Cartwright 2007). But apart from worries regarding 'external validity', i.e., the continued holding of the claim outside the trial population, the conditions under which many trials are conducted are far from the ideal, and for reasons able to raise concerns in patients. There are three sources of worry: outcomes likely to be biased; weakening standards; and suppression or delay of publishing results.

Biased outcomes. There has been a tendency for BMR to become more commercialised over recent years, that is, profit-oriented companies have replaced academic and other non-profit organisations in conducting medical research such as clinical trials. For instance, in 1991, only $20 \%$ of industry money for clinical trials went to

\footnotetext{
3 Global Forum for Health Research (2004b, 20).

4 To the extent that I have been able to verify it, European BMR is similar in many respects but less extreme.
} 
commercial research units such as contract-research organisations (CROs) and sitemanagement organisations (SMOs); by 1998, the figure had risen to 60\% (Getz 1999). In 2003, CROs alone played a substantial role in $64 \%$ of phase 1, 2, and 3 clinical studies, as compared with only $28 \%$ in 1993 (Shuchman 2007). ${ }^{5}$

Industry-sponsored research tends to have outcomes that are favourable for the tested drug (Bekelman et al. 2003). This could of course be explained if drugs reached trial stage only when there are very good reasons to believe that the drug is indeed effective. But if results are compared between those financed by industry and those by independent organisations, it turns out that there are differences. For instance, Als-Nielsen et al. (2003) find in a study of 370 randomized drug trials included in meta-analyses from Cochrane reviews that the experimental drug was recommended as the treatment of choice in $16 \%$ of trials funded by nonprofit organizations, but in $51 \%$ of trials funded by for-profit organizations.

Weakened standards. The commercialisation of research has also weakened the standards. Today, drugs are often tested on patients who are younger and more healthy than the target population. As a consequence, effectiveness may be exaggerated and side effects understated. Further, if the drug is tested against an existing product, the latter is often administered in insufficient doses or inadequate ways, which again makes the new drug appear more effective than it actually is. Moreover, more and more community physicians who have no training in research are involved, for instance, in the selection of patients (Bodenheimer 2000).

Suppressed and delayed publication. ${ }^{6}$ According to one study, 'Substantial numbers of clinical trials are never reported in print, and among those that are, many are not reported in sufficient detail to enable judgments to be made about the validity of their results' (Chalmers 1990, 1405). An unpublished report cannot be scrutinised by the public. Another study found long delays in the publication of results (Blumenthal et al. 1997). Especially when the research reveals side effects of already marketed drugs, this can have severe adverse consequences. Justin Biddle reports findings to the effect that Merck, the producer of Vioxx, mischaracterised the state of knowledge regarding its possible cardiovascular side effects between 2000 and 2004 and reported data on the drug inadequately (Biddle 2007). Moreover, it is becoming more frequent that trials are run at multiple sites such that only the pharmaceutical company has the whole set of data and can therefore control what is being analysed and published (Bodenheimer 2000). Researchers working on individual sites cannot run adequate tests as they have access only to subsets of the data and hence cannot publish results.

None of the points I summarised above establish that the drugs that have been approved by the FDA are necessarily unsafe or ineffective or both. But they do raise concerns about whether enough has been done to find out whether they are. That is, they primarily raise epistemic concerns. Since drugs that are approved can be marketed, moral and socio-economic consequences are immediate: an unsafe drug ought not to reach patients and companies ought not to reap profits

\footnotetext{
5 On CMOs in the context of commercialised research, see also Mirowski and Van Horn (2005).

6 As Jacoline Bouvy pointed out to me, the FDA now requires certain trials to be registered with clinicaltrials.gov, and medical journals will only publish results of registered trials, which makes suppression and delay of publication harder (albeit not impossible).
} 
Table 1 Relationship between research funding and global disease burden (GDB); financial data for 2001

\begin{tabular}{llcll}
\hline Condition & $\begin{array}{l}\text { GDB (in million } \\
\text { DALYs) }\end{array}$ & $\begin{array}{l}\text { R\&D funding } \\
\text { (Mill.U.S.\$) }\end{array}$ & \% of total GDB & $\begin{array}{l}\text { R\&D } \\
\text { funding/DALY } \\
\text { (U.S.\$) }\end{array}$ \\
\hline All & 1,470 & 105,900 & 100 & 72 \\
$\begin{array}{l}\text { HIV/AIDS + TB + } \\
\text { malaria }\end{array}$ & 167 & 1,400 & 11.4 & 8.4 \\
CVD & 148.19 & 9,402 & 9.9 & 63.45 \\
Diabetes & 16.19 & 1,653 & 1.1 & 102.07 \\
Malaria & 46.49 & 288 & 3.1 & 6.2 \\
TB & 34.74 & 378 & 2.3 & 10.88 \\
\hline
\end{tabular}

Source: De Francisco and Matlin $(2006,90)$

from them. This is just one example of how the epistemic, the moral and the socioeconomic interact. In the following subsections I will look at concerns that are primarily moral and social-economic.

\subsubsection{Moral failures}

Choice of research projects is a traditional philosophy-of-science topic, which, always to some and to a great extent in the context of BMR, has ethical ramifications. It is clear that there are enormous inequalities in the global allocation of funds to research different diseases. As Table 1 shows, communicable diseases such as HIV/AIDS, malaria and tuberculosis, the sufferers of which live mostly in third-world countries, receive only a fraction of the investment per share in the global disease burden as compared to first-world afflictions such as cardiovascular disease and diabetes. To quote just one figure, malaria, pneumonia, diarrhoea and tuberculosis together account for $21 \%$ of the global disease burden as measured in DALYs,${ }^{7}$ but receive only $0.31 \%$ of all public and private funds devoted to health research (Global Forum for Health Research 2004a, 122).

Perhaps issues of global justice aren't a concern for U.S. BMR. ${ }^{8}$ But U.S. patients' needs do not seem to be served too well either. ${ }^{9}$ Many of the new drugs the FDA approves target diseases that have the following properties (Angell 2004, 83ff.). They:

- are chronic, i.e., not curable, but treatable,

- are not lethal,

- affect wealthy people.

Examples include depression, diabetes, and high blood pressure. These are, however, conditions for which there already exist very effective medical drugs or for which

\footnotetext{
${ }^{7}$ DALYs are a measure of overall disease burden, combining mortality and morbidity. Each health state is assigned a number between zero (complete health) and one (death), which is multiplied with the number of years a person suffers from the disease or, in case of death, with the number of years the sufferer would have lived had he or she been fully healthy.

8 Though they should be, see Reiss and Kitcher (2009).

9 This double negative effect—on both developing world as well as the United States—is also emphasised by Joseph Stiglitz, see Stiglitz (2006a, Ch. 4).
} 
non-medical treatments such as exercise and diet often prove to be more effective than medical treatments. For example, in a comparative trial on patients with a high risk of developing diabetes, $29 \%$ in the placebo group, $22 \%$ in the treatment group, but only $14 \%$ in a group that underwent a diet and exercise programme developed the condition (ibid., 170). For a different example, in a study called ALLHAT (short for Antihypertensive and Lipid-Lowering Treatment to Prevent Heart Attack Trial) a generic diuretic turns out to be just as effective for lowering blood pressure as newer, branded and therefore far more expensive drugs (ibid., 94ff.).

Moreover, pharmaceutical companies appear to invent diseases. In order to be able to extend the patent life of Prozac, Eli Lilly renamed the drug and promoted it to treat premenstrual dysphoric disorder (PMDD), a condition previously not thought of as in need for medical treatment. Erectile dysfunction, female sexual dysfunction and social anxiety disorder are other prominent examples. ${ }^{10}$

\subsubsection{Socio-economic failures}

I now turn to the products of research. Contemporary U.S. BMR generates drugs with questionable medical value and of unknown safety and effectiveness. To make matters worse, the products are by and large not particularly innovative but all the more expensive. This too is an area where the three dimensions interact. Expensive healthcare makes access more difficult for poor people. And lack of innovation is as much an epistemic failure as it is socio-economic.

Innovativeness. Despite the pharmaceutical industry's claims to the contrary, it would be hard to maintain that it is as innovative as it says. For instance, 1,284 new drugs were approved by the FDA in the period 1990-2004. The FDA classified them as follows:

- $289(22.51 \%)$ constitute a 'significant improvement compared to marketed products in the treatment, diagnosis, or prevention of a disease' (of these, 183 or $14.25 \%$ of the total were 'new molecular entities' and 106 or $8.26 \%$ of the total were improved variations on existing drugs such as new formulations, new combinations or new manufacturers);

- $77.49 \%$ of the approved drugs were no better than existing drugs. ${ }^{11}$

This means that the overwhelming majority of 'new' drugs that do arrive in the market are slight modifications of existing substances (and adjustments were introduced just in order to be able to patent the entity), which have come to be known as 'me-too' drugs. Even if the me-too drug problem may sometimes be overstated, ${ }^{12}$ it is clear that the industry is hardly as innovative as it claims it is.

\footnotetext{
10 For more on 'disease mongering' see Public Library of Science (2006).

11 http://www.fda.gov/cder/rdmt/pstable.htm.

12 Detlef Niese, of Novartis, told me in personal conversation that whether a drug is effective or not often depends on the exact details of its composition and it is very hard to find out what will work. Thus new combinations or formulations of existing entities may be regarded as innovations even though they are not new molecular entities.
} 
It is also notable that the FDA requires drugs to be tested only relative to placebos (except in ethically highly problematic cases). This means that an FDA approval is, at best, a signal that the approved drug is better than taking a sugar pill, not that it's better than an existing treatment. But as we will see, FDA approval means less than that. Importantly, the research dollars spent on drugs that are no better than existing products could be spent on new treatments that have genuine medical value. The current system therefore involves high social opportunity costs. Direct, non-economic costs are created by animal and human testing of new drugs that have no benefit.

Exploding health costs. U.S. patients have to pay far more for their drugs than consumers in comparable countries. Spending in the U.S. for prescription drugs was $\$ 227.5$ billion in 2007, more than five times the 1990 figure (which was $\$ 40.3$ billion; see Kaiser Family Foundation 2008; Hartman et al. 2009). This was about $\$ 753$ per capita in 2007. In the same year, Canadians spent some (U.S.) $\$ 538$ per capita. ${ }^{13}$ The disparity between the two countries is even more extreme when one looks at the total health administration costs. According to one study, U.S. citizens paid $\$ 1,059$ on health in 1999, as compared with $\$ 307$ in Canada (Woolhandler et al. 2003, 768). ${ }^{14}$

\subsection{Causes}

The causes of the malaise of U.S. BMR are unlikely to be found in ignorance or disagreement about the epistemic, moral and socio-economic matters that were described above in the biomedical community. Plainly, a biomedical scientist does not need a philosopher to tell her how to run a clinical trial. To be sure, there are some disagreements about data interpretation-most notably between frequentists and Bayesians (see for instance Mayo 1996 for the frequentist and Howson and Urbach 2005 for the Bayesian perspective) — and about what clinical trials can and cannot achieve (see for instance Worrall 2002), but most of the points made above are well known and relatively uncontroversial among scientists. Perhaps not everyone will agree that U.S. BMR should prioritise research into tropical diseases but global health inequalities too are something Western biomedical practitioners increasingly worry about (for a survey of issues and responses, see McGoey et al. forthcoming).

Nor, in my view, is the profit motive many see as the force driving the commercialisation of research a factor that explains much. Greed is an epiphenomenon. People, scientists and non-scientists, government- or industry-sponsored, simply respond to incentives. And the incentives, whether material or non-material, are provided by the structures and institutions within which research (or any other activity) is practised. The appropriate place to look for the causes of the status quo are is therefore the aspects of the regulation that have helped to create the current system.

Throughout, the health care legislation in the United States since 1980-described by some as 'watershed year' for BMR (e.g. Angell 2004; Mirowski and Van Horn

\footnotetext{
13 Morgan et al. (2008, 10). The report quotes a figure of 577.70 Canadian Dollars, which I converted into U.S. Dollars using an average exchange rate for 2007. Using an average was necessary because the exchange rate is very volatile, ranging from 0.84 to 1.09 USD/CAD in 2007.

14 Though the exact figures are subject to doubt. See Aaron (2003).
} 
2005) - has been extremely business friendly, thus seldom acting with the patient's welfare in mind and doing violence to the production of scientific knowledge. Inadequate regulation - both the failure to regulate certain practises as well as the introduction of new regulations with adverse effects - has created a system in which everyone seems to profit: companies and their stock holders by high sales and profit margins; doctors, by gifts and financial contributions from the industry; academic researchers, by the possibility to patent the fruits of their research; politicians, by board memberships in the industry and campaign donations; regulators, by so-called 'user-fees', paid for by the industry; and - apparently_patients, by an allegedly highly innovative industry that is spending billions to find new treatments for their health problems. We have already seen that these appearances deceive, at least as regards the patients' welfare. Let us now examine more specifically the areas in which the industry seems to be inadequately regulated.

\subsubsection{Advertising and marketing}

Spending on direct-to-customer (DTC) advertising by the U.S. pharmaceutical industry shot up from $\$ 55$ million in 1991 to over $\$ 2.5$ billion in 2000 and 4.2 billion in 2005 (Rosenthal et al. 2002; Donohue et al. 2007). DTC advertising has at least two adverse effects. First, it makes consumers believe they suffer from a condition that can and should be treated by using a drug, a condition that otherwise would have gone unnoticed and for which treatment would not have been required or for which other forms of treatment are just as effective, if not more so (e.g., psychotherapy for depression). Second, for a given condition or disease patients often request a particular brand-name drug although a much cheaper and sometimes more effective and safer generic version is available (Wilkes et al. 2000).

The bulk of the pharmaceutical companies' spending on marketing, however, aims to influence doctors' prescription behaviour rather than the patients themselves. An army of sales representatives is employed by the industry with budgets to give doctors samples, pay for expensive lunches and dinners or other gifts. Sometimes doctors charge fees for their time listening to a sales representative (Chin 2002). Billions of dollars are spent on supporting medical congresses, meetings and continuing education events (Moynihan 2003). Further, firms advertise their products in medical journals, some of which depend on industry ads for their existence. The marketing and advertising budgets as a percentage of sale in the industry average $34.9 \%$ over the decade 1990-2000 (Kreling et al. 2001, 45), as compared with an average share of between $10.9 \%$ (1990) and $13.7 \%$ (2000) of sales for R\&D spending. Marketing and advertising therefore help to inflate health care costs and to divert resources away from those with greatest needs to those with the largest willingness to pay.

\subsubsection{Corruption}

Nearly every type of player in U.S. BMR receives benefits, financial or in-kind, from the pharmaceutical industry. Some examples include: 
- Doctors. 94\% of U.S. physicians have been reported to profit from the pharmaceutical industry in one way or another (Campbell et al. 2007). One important canal is the payment of 'finder's fees' for community physicians who sign up patients in clinical trials (see for instance Christensen and Orlowski 2005).

- The FDA. The pharmaceutical industry pays so-called user fees to the FDA for expedited drug approval (Hilts 2003). Since 1992, the proportion of the federal government's contribution to FDA funding has been declining, while that provided by industry has risen steadily (Harris 2004). Today, more than half of the employees of the FDA are dependent on user fees in the sense that their jobs would not exist were it not for industry money (Angell 2004, 208-209). This matters because the percentage of funding devoted to the approval of new drugs has risen from $53 \%$ in 1992 to $79 \%$ in 2003 , while the percentage of funding devoted to surveying existing drugs has correspondingly declined (Harris 2004).

- Politicians. In 2002, the pharmaceutical industry employed 675 lobbyists in Washington, which means more than one for each member of Congress and nearly seven for each U.S. senator. Of these, 26 were former members of Congress. Various politicians are former industry members (e.g., Donald Rumsfeld used to be CEO, president and chairman of G. D. Searle; George Bush Sr. was on the Eli Lilly board of directors). In the 1999-2000 election cycle, pharmaceutical companies gave $\$ 20$ million in direct campaign contributions plus $\$ 65$ million in soft money (Angell 2004, Ch. 11).

Failure to regulate these financial flows creates all three types of deficiencies. Standards for drug research and approval are watered down. Projects with dubious medical but high expected commercial value are pursued. The costs of health care are inflated.

\subsubsection{Commercialised research}

Both basic as well as clinical research has become dramatically more commercialised in the past 20 years. ${ }^{15}$ The Bayh-Dole Act and the Stevenson-Wydler Act (both 1980) gave universities, small businesses and the National Institutes of Health (NIH) patent-control over their inventions stemming from government-funded research and the ability to charge royalties to the pharmaceutical industry in exchange for licenses. This has helped to create the boom in biotechnology start-up companies, but it has also affected research done at universities. More and more academic researchers see themselves now as partners of industry rather than as pursuing some independent good. There has also been a considerable brain drain from universities to small biotech firms and other companies.

Clinical research has become more commercialised by the replacement of academic medical centres with for-profit contract research and site maintenance organisations, as mentioned above. To give additional figures, $71 \%$ of industry-sponsored clinical trials were outsourced to academic medical centres in 1991. By 2001 this percentage had dropped to $36 \%$ (Heffner 2004). This in turn has put pressure on academic med-

15 Commercialisation of scientific research is a much broader trend and not confined to medical research. See for instance Krimsky (2003), Mirowski and Sent (2002), Wilholt (2006), and Carrier (2008). 
ical centres to compete with the for-profit organisations. In response, several leading universities have formed networks. Today, two thirds of academic medical centres hold equity in start-ups that sponsor some of the research conducted in these centres (Bekelman et al. 2003).

\subsubsection{Profits and patents}

The pharmaceutical industry makes exorbitant profits with margins that are much higher than those of other industries. In the 1990s, the top-ten pharmaceutical companies had a profit margin of about $25 \%$ of sales while the industry average was about 3-5\% (Public Citizen 2003). In the Fortune 500 list, pharma was, with a profit margin of $19.1 \%$, still the second most profitable industry in 2008, topped only by mining/crude-oil production. ${ }^{16}$

Above-average profits are likely to be due to the monopoly power companies have over selling their inventions. The U.S. Patent and Trademark Office (USPTO) grants 20-year patents to inventor firms, in the form of a patent and the FDA exclusive marketing rights. The 20-year period is reduced by the time it takes the company to run clinical trials and get FDA approval such that effective patent life is about 14 years (Public Citizen 2001, 16). However, companies can stretch that period considerably in a variety of ways. For instance, if a branded drug manufacturer sues a generics company for patent infringement, FDA approval of the generic drug will be automatically delayed by 30 months - even if there is no basis for the case. So-called 'citizen petitions' can be filed in which safety concerns about a generic are raised, which can also delay approval. Further, if a drug is tested in children an additional 6 months of protection is granted. This often results in drugs being tested in children even if the drug treats adult diseases such as high blood pressure. And since every aspect of a drug can be patented, including new uses, dosage forms, combinations of old drugs, coatings and colours of pills, patent thickets are created around new substances (Angell 2004, Ch. 10).

\section{Existing proposals for a solution}

I will briefly consider three existing proposals to reform BMR. The first, developed by the political philosopher Thomas Pogge, is motivated mainly by concerns for global justice. As explained above, global justice is just one facet of the problems relevant here. Nevertheless it is the most detailed reform plan there is to date, and it brings out some ideas important for appreciating my own alternative.

Pogge's proposal is based on three main ideas (Pogge 2005; Hollis and Pogge 2008). First, inventor firms should be rewarded with a 10-year monopoly on their inventions after market approval. Second, during this time they are rewarded, out of public funds, in proportion to the impact of their invention on the global disease burden. Third, the cost of this scheme is borne by the governments of advanced countries. The idea is to make essential medicines available to all by keeping their prices low while at

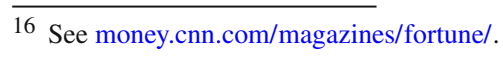


the same time providing financial incentives for companies to invent drugs that target conditions that have a high disease burden, no matter where they obtain.

Pogge's proposal focuses on the moral failings and only the moral failings of current BMR. It aims to realign research priorities of U.S. pharmaceutical companies with the plights of the global poor. Supposing that the measures he envisages are successful, the proposal neglects the other dimensions of shortcomings. Specifically:

- Since it basically retains the current intellectual-property system-accepting the view that without it there would be no or considerably less innovation-it also retains the negative effects of that system. As I will explain in detail below, the existence of monopolies tends to induce rent-seeking behaviour such as the creation of legal thickets around patents, corruption and aggressive marketing, and there is no reason to believe that there should be any less rent-seeking in Pogge's scheme than in the current system.

- The current system is economically inefficient, a fact mirrored in high health care costs. In Pogge's scheme the inefficiency is likely to be maintained because it creates a dual system with the newly created health impact fund existing alongside traditional patent protection.

- The current system is skewed towards patentable solutions: drugs, gadgets, forms of administering treatments and so on. But many effective solutions are not patentable because they involve for instance environmental approaches. Unpatentable solutions would remain neglected - a moral and socio-economic shortcoming.

- A system in which innovators are rewarded with a monopoly on their inventions provides incentives to hide research results. No idea is ever entirely new and always builds upon earlier ideas (see below discussion on 'innovation chains'). Medical research is strongly characterised by this feature. It has already been mentioned that pharmaceutical companies almost always develop entities that originate elsewhere, mostly in basic research done at universities. Pogge's system would therefore perpetuate an epistemic shortcoming.

Joseph Stiglitz, a Nobel-prize winning economist, proposes a similar solution with four elements (Stiglitz 2006a, Ch. 4, 2006b):

(1) Introducing separate intellectual property regimes for different levels of development;

(2) Provision of drugs at cost to developing countries;

(3) Compelling innovating firms to provide licenses to (third-world) generics producers in the case of lifesaving drugs;

(4) Creating a Medical Prize Fund (from public and philanthropic money).

Since Stiglitz' plan also leaves the current IP regime basically untouched, most of the criticisms of Pogge's proposal carry over. In particular, it is hard to see how pharmaceutical companies could be motivated to invent life-saving drugs to treat third-world diseases (rather than continuing to develop products that sell in the U.S.) unless the expected profit from doing so is at least as high as the expected profit from the projects currently pursued. But that means that the Medical Prize Fund must award artificially high prizes - and is therefore socio-economically inefficient. 
Philosopher of science James Robert Brown opts for a more radical reform of the system. In his proposal, which he calls 'scientific socialism', there are two major changes relative to the current regime (Brown 2008, 209): (a) elimination of patents in the domain of medical research; (b) adjustment of public funding to appropriate levels. Brown's proposal is motivated by the desire to eliminate the adverse effects of research driven by commercial interests. Replacing a system that is dominantly market-driven by one that is exclusively public-driven might not bring about the desired change, however. Among other things, government-funded research does not have great precedents to speak for it. Some of the more recent changes that commercialised BMR have been introduced because the then-status quo in which the government occupied a larger role was seen as inadequate. The Bayh-Dole Act, for instance, was passed because of the 30,000 patents the government had amassed by the late 1970s, only $5 \%$ were commercially licensed. The fruits of publicly sponsored research were therefore of no use to the general public.

\section{A Millian alternative}

I call the proposal I am going to describe in what follows (aspects of which were developed in a joint work with Philip Kitcher; see Reiss and Kitcher 2009) 'Millian' because it stresses the importance of individuality, it takes pluralism as an epistemic norm and it is committed to social progress and the protection of minority interests. The proposal has the following four components: changes in the IP regime; creation of an independent clinical research institute; aligning innovators' and patients' interests; and additional regulation. Let us consider each in turn.

\subsection{The intellectual property regime}

I agree with Brown that the most important aspect of regulation that has to be changed in order to address the failings of current BMR is the system of intellectual property (IP) protection. Rather than enabling innovation-as standard economic theory predicts - we have good reasons to believe that patent-induced monopolies cause (a) the stifling of innovation because of innovation chains (every new idea is built on a previous idea, and if the previous idea is protected, the new idea cannot be developed); (b) redundant research; and (c) rent-seeking behaviour (Boldrin and Levine 2008, Ch. 9). All three consequences are prominent in U.S. BMR. To give just one example of how patents can stifle innovation, consider a statement by Peter Ringrose, chief scientific officer at Bristol-Myers: 'there are more than 50 proteins possibly involved in cancer that the company was not working on because the patent holders either would not allow it or were demanding unreasonable royalties' (Pollack 2001). That many 'new' drugs that are approved for marketing aren't genuinely new and therefore to a large extent redundant has been described above.

Let me explain the third point about the connection between monopolies and rentseeking in slightly greater detail. A monopolist charges a higher price for his good (which he can because he is its sole supplier) and therefore reap a higher profit than an otherwise identical firm in a competitive structure. The difference between the two 
profit levels is called the monopoly rent. Monopoly rents produce incentives to engage in non-economic behaviour such as attempts to keep potential competitors out of the market or to protect the monopoly through favourable legislation. This kind of behaviour is called rent-seeking. Examples of typical rent-seeking behaviour that have been observed in U.S. BMR are excessive advertising and marketing, corruption, lobbying, the creation of patent thickets and so on.

Plainly, that strong IP protection can cause the stifling of innovation, redundant research and rent-seeking does not entail that this is the factor that is responsible for these facts about current BMR nor that moderating IP is an effective strategy to combat them. The former-historical—question is one that lies neither within the topic nor the scope of this paper. So let us look at the question concerning effective strategies.

We learn from Mill-in his utilitarian moments-that social institutions need to be adapted to the time, place and context where they operate. The institution of IP is no exception. As mentioned above, economists sometimes argue that IP must be protected because without protection nobody would invest in the production of ideas. But, as we also learn from Mill, such a claim is at best true 'in the abstract': if actors are motivated only by greed and if no disturbing factors operate. A disturbing factor that has been shown to make a difference is time: in mathematical models in which copying an idea takes time, there can be innovation without IP protection (Boldrin and Levine 2002). Another crucial factor is the demand elasticity of the new product (ibid.). Since this is likely to be different for different industries (in particular different within the spectrum of medical products; for example, different for life-saving than for lifestyle medicines), there is no reason to believe that an optimal IP regime is the same for all countries and all times but even within a country and at a point in time for all industries.

Because of the complexity of the matter and because so little is known empirically (though for a beginning, see Boldrin and Levine 2008), to my mind the right way to approach the question is by 'adaptive management'. Sandra Mitchell explains the idea as follows (Mitchell 2009, 97):

For the purposes of this discussion, the most important thing to notice about adaptive management is that it modifies the predict-and-act model to be an iterative process of predict, act, establish metrics of successful action, gather data about consequences, predict anew, establish metrics of successful action, act, gather data about consequences, predict anew.... Adaptive management is a dynamic, iterative, feedback-rich strategy for decision making that matches the dynamic, feedback-dependent reality of complex systems.

Rather than introducing a new system in one fell swoop, as Pogge, ${ }^{17}$ Stiglitz and Brown propose, adaptive management suggests a piecemeal approach: (1) gradually reduce patent duration and/or breadth, ${ }^{18}(2)$ observe consequences on innovation, profits and

\footnotetext{
17 David Levine has told me in personal conversation that he is sceptical about scheme's such as Pogge's precisely because we don't know what the consequences will be.

18 By breadth I mean the range of ideas that are considered worthy of patent protection. One of the most glaring examples of currently excessive breadth is the patenting of turmeric for the use of wound healing. See Anuradha (2001).
} 
rent-seeking behaviour, and (3) assess whether (a) the intervention improved on the status quo and (b) a satisfactory outcome has been reached. If the answer to (a) is yes but to (b) no, go back to (1). If the answer to (a) is no, redesign the intervention on the basis of what has been learned and go back to (1). Stop this circle once the answer to (b) is yes but continue to monitor the crucial outcome parameters (innovation, profits and rent-seeking behaviour).

The pivotal question is what should count as a 'satisfactory outcome'. With respect to any single parameter, an optimum should be relatively easy to determine. Suppose there is indeed a causal relationship between patent life and the rate of innovation. ${ }^{19}$ Holding fixed other causes of innovations, changing patent life should then change the rate of innovation. Once the functional relationship between the two variables has been determined empirically, the function can be maximised with respect to patent life, and patent life fixed at the optimum length. There is no guarantee, of course, that the optimum for the rate of innovation coincides with the optimum for other parameters such as profits (optimum outcome $=$ average rate of return for the given level of risk) or the different forms of rent-seeking (optimum outcome = zero). A compromise must be sought and therefore I speak of a 'satisfactory outcome'.

\subsection{Independent clinical testing}

Whereas the reform of the IP system focuses primarily on the social failures-needless pseudo-innovations and rent-seeking - a reform of the clinical testing apparatus is due because of its epistemic shortcomings. The root of the problem here is, to put it bluntly, that the same people who are responsible for a pharmaceutical company's profits are also responsible for drug testing and reporting research results. It is not surprising that not everyone facing these conflicts of interest acts in a way that promotes patients' welfare.

The problem of disentangling patients' and commercial interests can be approached from various angles. Justin Biddle proposes that the FDA adopt an adversarial system for drug approvals (Biddle 2007, 34):

Under this system, two groups of advocates would argue before a panel of judges over such questions as whether-and under what conditions - a drug should be allowed on the market, and whether a drug that is already on the market should remain so. One set of advocates would consist of industry or industry-sponsored scientists who would argue on behalf of a pharmaceutical company. The other set would consist of scientists who receive no funding from pharmaceutical companies; these advocates would argue on behalf of the public that, for example, a given drug is sufficiently dangerous that it should be taken off the market. The panel of judges could consist, for example, of FDA or university scientists who are independent of any industry that might have a stake in the outcome of the proceedings.

\footnotetext{
19 To keep matters simple and straight. The quality of the innovations matters too of course. More on that below in Sect. 5.3.
} 
Enacting Biddle's proposal would probably constitute an improvement over the current situation but it cannot solve even the epistemic problem all by itself. The 'scientists who receive no funding from pharmaceutical companies' could at best point to flaws in the drug companies' reasoning. Even that would be difficult as long as the data continue to be provided by industry, which, in an adversarial system, has every motivation to present its case in a favourable light. Absent additional clinical trials, the public's advocates could not provide independent reasons in favour or against approving a drug.

Apart from the need for funding, the possible sources of which Biddle does not discuss, conducting additional trials would lead into a dilemma. The advocates of the public will either, as in a genuine adversarial system and like the pharmaceutical companies, manipulate aspects of trial design such as to make favourable outcomes likely and filter results or conduct the trials and report outcomes in a neutral manner. If they do the former, it will be virtually impossible for the judges to come to the right conclusion: two bad pieces of evidence don't make a good one. If they do the latter, conducting also industry trials would seem wasteful.

I therefore see no other solution than to leave the running of clinical trials to an independent body committed to neutral hypothesis testing and overlooked by a board whose members represent different stakeholders. Funding could be either fully public (as Brown proposes) or by membership fees-every organisation that seeks to test a new drug has to pay a fee that is independent of the number and outcomes of the trials conducted by the institute (see Reiss and Kitcher 2009) or by a mix of the two. ${ }^{20}$ As long as financial independence and quality control of clinical testing is guaranteed, it does not matter in principle whether the actual trials are conducted by university researchers or the members of a centralised 'Institute for Clinical Trials'. Some considerations point to favouring a more centralised approach. After the Bayh-Dole Act, university research itself has become commercialised, and many academics see themselves as partners of industry rather than pursuers of an independent good (Krimsky 2003). University research and entrepreneurship are entangled, for instance by personal financial ties of academics to industry and university medical centres owning equity in businesses (Bekelman et al. 2003). At least as things stand today, university researchers may not be the best choice if independence from industry is the goal. Moreover, centralising clinical research would help enforcing quality standards as well as making them subject to public scrutiny. On the other hand, as long as there is disagreement regarding the precise nature of the standards, and there is good reason to believe that at least some controversies (such as that between frequentists and Bayesians) are here to stay, a pluralist approach with many independent though regulated trial centres may be preferable. As usual, there is no ideal solution.

Whether independent clinical research constitutes an improvement over the status quo can be determined relatively easily. The goal is to be in the position to know a new treatment's safety and efficacy prior to approval. While it is clear that we can never know for certain that this goal has been reached, there are simple metrics of suc-

20 The new system could be combined with an adversarial drug approval process, which, for instance, takes into account further evidence and determines whether the evidence indicates that the drug is socially valuable. 
cess. When for instance phase-IV trials (so-called post-marketing surveillance trials) continue to contradict phase-III trials (i.e., large pre-approval trials), and in particular when differences are noticeable soon after approval (such as in the Vioxx case, see Biddle 2007), we know that something went wrong.

\subsection{Aligning commercial and (global) patients' incentives}

Above I have argued that the status quo is morally deficient because drugs that come to the market often (a) are no better than current drugs, (b) target conditions that either need no treatment or for which there are alternative, non-medical treatments available, and (c) neglect the diseases of the poor. Problems (a) and (b) can be ameliorated if not solved by stricter approval requirements. As already discussed, currently a drug has to be shown to be effective only relative to a placebo except in cases where it would be highly unethical not to treat patients. Instead, the FDA should require drugs to have genuine medical benefits, that is, to be better than all existing therapies, including non-medical options.

The problem of neglected diseases requires additional government action. Reiss and Kitcher (2009) advocate the creation of 'Global Institutes of Health', in analogy with the U.S. National Institutes of Health but committed to addressing global health issues. But direct funding of research projects would only be one means to incentivise neglected-disease research. So-called advance purchase commitments (APCs, also known as advance market commitments or AMCs) are another, and so are awards and tax breaks for research into neglected diseases. ${ }^{21}$ Adaptive management can be used to determine which of the different measures promotes global health outcomes most efficiently and effectively.

\subsection{Additional stricter regulation}

While the remodelling of the IP system should result in a reduction in rentseeking activity on part of the pharmaceutical companies, the reform can be supported by outlawing - and enforcing the ban on-certain unfavourable practises. There is no reason why pharmaceuticals should be advertised to patients, so DTC advertising should be prohibited. Moreover, the various ways in which drug companies lure doctors into prescribing their medications can and should be blocked. This concerns industry sponsorship of continuing education events, advertising in medical journals, direct payments, for example in the form of consulting fees, gifts and dinners as well as 'finders' fees'. In the new system there will be much less incentive for drug companies to engage in these activities. Nevertheless, prohibiting what is not prohibited now and enforcing existing regulation provides an additional signal that these practises are socially harmful.

\footnotetext{
21 This is also a type of mechanism Matthias Adam advocates: 'A reward system that places a particular premium on the investigation of neglected research topics might be capable of securing a balanced and comprehensive scientific research program while allowing scientists or research groups to follow their own preferences' (Adam 2008, 238-239).
} 


\section{Conclusion}

This paper began by arguing that the organisation of biomedical research should be a philosophy of science topic. I made the case by pointing out how more traditional philosophy of science issues such as that of theory choice and choice of research projects are intertwined with issues that are more traditionally dealt with in ethics, for instance patient welfare and global justice. The proposal outlined here too shows how solutions affect the epistemic, moral and socio-economic dimensions at the same time. Most importantly, less patent protection means lower profits, which means smaller rents to be sought, which means less incentives to 'cheat' when it comes to establishing whether or not a drug is safe and effective. Likewise, requiring drugs to be tested against an existing treatment is not only an epistemic standard but a social one in that it makes socially inefficient 'invention' less likely.

Let me emphasise that the specific proposal outlined here is at best a rough sketch of a reform. Some of the empirical facts one would need to know in order to give more detailed recommendations, especially regarding optimal IP regimes, are simply not well enough understood. But what we can tell with reasonable certainty is that the current system is deficient, epistemically, morally and socio-economically. I have tried to defend a specific proposal I believe to be more convincing than some existing proposals. But more important is that if philosophy of science is to be more socially relevant, it should be concerned with issues of the kind raised in this paper.

Acknowledgments Research for this paper has been financially supported by two projects funded by the Spanish ministry of education: FFI2008-01580 and CONSOLIDER INGENIO CSD2009-0056. My special thanks go to Katie Plaisance and Carla Fehr for extensive and highly helpful comments on previous versions of this paper and their editorial patience. Errors remain, as usual, my responsibility.

Open Access This article is distributed under the terms of the Creative Commons Attribution Noncommercial License which permits any noncommercial use, distribution, and reproduction in any medium, provided the original author(s) and source are credited.

\section{References}

Aaron, H. (2003). The costs of health care administration in the United States and Canada-questionable answers to a questionable question. New England Journal of Medicine, 349(8), 801-803.

Adam, M. (2008). Promoting disinterestedness or making use of bias? Interests and moral obligation in commercialized research. In M. Carrier, D. Howard, \& J. Kourany (Eds.), The challenge of the social and the pressure of practice: Science and values revisited (pp. 235-255). Pittsburgh, PA: Pittsburgh University Press.

Als-Nielsen, B., Chen, W., Gluud, C., \& Kjaergard, L. (2003). Association of funding and conclusion in randomized drug trials: A reflection of treatment effect of adverse events? Journal of the American Medical Association, 290(7), 921-928.

Angell, M. (2004). The truth about the drug companies. New York, NY: Random House.

Anuradha, R. V. (2001, May 20). Biopiracy and traditional knowledge. The Hindu.

Bekelman, J., Li, Y., \& Gross, C. (2003). Scope and impact of financial conflicts of interest in biomedical research. Journal of the American Medical Association, 289(4), 454-465.

Biddle, J. (2007). Lessons from the Vioxx debacle: What the privatization of science can teach us about social epistemology. Social Epistemology, 21, 21-39.

Blumenthal, D., Campbell, E., Anderson, M., Causino, N., \& Louis, K. (1997). Withholding research results in academic life science. Journal of the American Medical Association, 277(15), 1224-1228. 
Bodenheimer, T. (2000). Uneasy alliance. New England Journal of Medicine, 342(20), 1539-1544.

Boldrin, M., \& Levine, D. (2002). Perfectly competitive innovation. Research Department Staff Report 303. Minneapolis, MN.

Boldrin, M., \& Levine, D. (2008). Against intellectual monopoly. Cambridge: Cambridge University Press.

Brown, J. R. (2002). Funding, objectivity and the socialization of medical research. Science and Engineering Ethics, 8, 295-308.

Brown, J. R. (2004). Money, method, and medical research. Episteme, 1, 49-59.

Brown, J. R. (2006). Regulation and research: Approaches to market failures in medicine. In Commerce, politics and science conference, Notre Dame.

Brown, J. R. (2008). The community of science ${ }^{\circledR}$. In M. Carrier, D. Howard, \& J. Kourany (Eds.), The challenge of the social and the pressure of practice: Science and values revisited (pp. 189216). Pittsburgh, PA: Pittsburgh University Press.

Campbell, E., Gruen, R., Mountford, J., Miller, L., Cleary, P., \& Blumenthal, D. (2007). A national survey of physician-industry relationships. New England Journal of Medicine, 356(17), 1742-1750.

Carrier, M. (2008). Science in the grip of the economy: On the epistemic impact of the commercialization of research. In M. Carrier, J. Kourany, \& D. Howard (Eds.), The challenge of the social and the pressure of practice: Science and values revisited (pp. 217-234). Pittsburgh, PA: University of Pittsburgh Press.

Cartwright, N. (2006). Well-ordered science: Evidence for use. Philosophy of Science, 73, 981-990.

Cartwright, N. (2007). Are RCTs the gold standard? BioSocieties, 2(2), 11-20.

Chalmers, I. (1990). Underreporting research is scientific misconduct. Journal of the American Medical Association, 263(10), 1405-1408.

Chin, T. (2002, May 6). Drug firms score by paying doctors for time. American Medical News.

Chow, S.-C., \& Liu, J.-P. (2002). Design and analysis of clinical trials: Concepts and methodologies (2nd ed.). Hoboken, NJ: Wiley.

Christensen, J., \& Orlowski, J. (2005). Bounty-hunting and finder's fees. IRB: Ethics \& Human Research, 27(3), 16-19.

Cohen, J., \& Gürtler, R. (2001). Modeling household transmission of American trypanosomiasis. Science, 293, 694-698.

De Francisco, A., \& Matlin, S. (2006). Monitoring financial flows for health research 2006: The changing landscape of health research for development. Geneva: Global Forum for Health Research.

Donohue, J., Cevasco, M., \& Rosenthal, N. (2007). A decade of direct-to-consumer advertising of prescription drugs. New England Journal of Medicine, 357, 673-681.

Getz, K. (1999). AMCs rekindling clinical research partnerships with industry. Boston: Centerwatch.

Global Forum for Health Research. (2004a). The 10/90 report on health research 2003-2004. Geneva: Global Forum for Health Research.

Global Forum for Health Research. (2004b). Monitoring financial flows for health research (Vol. 2). Geneva: Global Forum for Health Research.

Harris, G. (2004, December 6). At F.D.A., strong drug ties and less monitoring. New York Times.

Hartman, M., Martin, A., McDonnell, P., Catlin, A., \& the National Health Expenditure Accounts Team. (2009). National health spending in 2007: Slower drug spending contributes to lowest rate of overall growth since 1998. Health Affairs, 28(1), 246-261.

Heffner, S. (2004, March). Beyond the CRO. Contract Pharma.

Hilts, P. (2003). Protecting America's health: The FDA, business, and one hundred years of regulation. Chapel Hill, NC.: University of North Carolina Press.

Hollis, A., \& Pogge, T. (2008). The health impact fund: Making new medicines accessible for all. New Haven, CT: Incentives for Global Health.

Howson, C., \& Urbach, P. (2005). Scientific reasoning: The Bayesian approach. Chicago and LaSalle, IL: Open Court.

Kaiser Family Foundation. (2008). Prescription drug trends. Menlo Park, CA: Kaiser Family Foundation.

Kincaid, H. (2004). Contextualism, explanation and the social sciences. Philosophical Explorations, 7(3), 201-218.

Kincaid, H., Dupré, J., \& Wylie, A. (Eds.). (2007). Value-free science? Ideals and illusions. Cambridge: Cambridge University Press.

Kincaid, H., \& McKitrick, J. (Eds.). (2007). Establishing medical reality: Essays on the metaphysics and epistemology of science. Heidelberg: Springer. 
Kitcher, P. (1993). The advancement of science. Oxford: Oxford University Press.

Kitcher, P. (2001). Science, truth and democracy. Oxford: OUP.

Kreling, D., Mott, D., Wiederholt, J., Lundy, J., \& Levitt, L. (2001). Prescription drug trends: A chartbook update. Menlo Park, CA: Kaiser Family Foundation.

Krimsky, S. (2003). Science in the private interest: Has the lure of profits corrupted biomedical research? Lanham, MD: Rowman \& Littlefield.

Longino, H. (1990). Science as social knowledge. Princeton, PA: Princeton Universty Press.

Longino, H. (2002). The fate of knowledge. Princeton, PA: Princeton Universty Press.

Mayo, D. (1996). Error and the growth of experimental knowledge. Chicago, IL: University Press.

McGoey, L., Reiss, J., \& Wahlberg, A. (forthcoming). The health complex: Progress and pathologies in global health funding and governance. BioSocieties.

Mirowski, P., \& Sent, E.-M. (Eds.). (2002). Introduction. Science bought and sold: Essays in the economics of science. Chicago, IL: University of Chicago Press.

Mirowski, P., \& Van Horn, R. (2005). The contract research organization and the commercialization of scientific research. Social Studies of Science, 34(4), 503-548.

Mitchell, S. (2009). Unsimple truths. Chicago, IL: University of Chicago Press.

Morgan, S., Raymond, C., Mooney, D., \& Martin, D. (2008). The Canadian RX atlas (2nd ed.). Vancouver, BC: Centre for Health Services and Policy Research.

Moynihan, R. (2003). Who pays for the pizza? Redefining the relationships between doctors and drug companies. British Medical Journal, 326, 1189-1196.

Pogge, T. (2005). Human rights and global health: A research program. Metaphilosophy, 36(1/2), 182-209.

Pollack, A. (2001, January 8). Bristol-Myers and Athersys make deal on gene patents. New York Times.

Public Citizen. (2001). Rx R\&D myths: The case against the drug industry's R\&D "scare card". Washington, DC: Public Citizen.

Public Citizen. (2003). 2002 Drug industry profits: Hefty pharmaceutical company margins dwarf other industries. Washington, DC: Public Citizen.

Public Library of Science. (2006). Special issue on disease mongering. PLoS Medicine, 3(4).

Putnam, H. (2002). The fact/value dichotomy and other essays. Cambridge, MA: Harvard University Press.

Reiss, J., \& Kitcher, P. (2009). Biomedical research, neglected diseases and well-ordered science. Theoria, 24(3), 263-282.

Risse, M. (forthcoming). The grounds of justice. Princeton, NJ: Princeton University Press.

Rosenthal, M., Bernt, E., Donohue, J., Frank, R., \& Epstein, A. (2002). Promotion of prescription drugs to consumers. New England Journal of Medicine, 346(7), 498-505.

Selgelid, M. (2005). Ethics and infectious disease. Bioethics, 19(3), 272-289.

Shuchman, M. (2007). Commercializing clinical trials-risks and benefits of the CRO boom. New England Journal of Medicine, 357(14), 1365-1368.

Stiglitz, J. (2006a). Making globalization work. New York, NY: Norton.

Stiglitz, J. (2006b). Scrooge and intellectual property rights: A medical prize fund could improve the financing of drug innovations. British Medical Journal, 333, 1279-1280.

Wilholt, T. (2006). Design rules: Industrial research and epistemic merit. Philosophy of Science, 73(1), 66-89.

Wilkes, M., Bell, R., \& Kravitz, R. (2000). Direct-to-consumer prescription durg advertising: Trends, impact, and implications. Health Affairs, 19(2), 110-128.

Woolhandler, S., Campbell, T., \& Himmelstein, D. (2003). Costs of health care administration in the United States and Canada. New England Journal of Medicine, 349, 768-775.

Worrall, J. (2002). What evidence in evidence-based medicine. Philosophy of Science, 69, S316-S330. 